Original Article

\title{
Knowledge about, attitudes towards, practices regarding Taenia solium cysticercosis among people attending an epilepsy clinic in India
}

\author{
Pratyaksha Sankhyan, Sahil Gupta, Gagandeep Singh* \\ Department of Neurology, Dayanand Medical College, Ludhiana 141001, Punjab, India
}

\section{A R T I C L E I N F O}

Article history:

Received 21 January 2014

Accepted 11 March 2015

Available online 6 May 2015

Keywords:

Cysticercosis

Knowledge

Attitude

Practices

Taenia solium

\begin{abstract}
A B S T R A C T
Background: Taenia solium cysticercosis is one of the commonest, but potentially eradicable, causes of seizures in India. Eradication and appropriate control should incorporate educational interventions regarding the infestation and this requires an assessment of knowledge about, attitudes towards and practices (KAP) regarding the disorder.

Aim: We undertook a KAP survey regarding T. solium cysticercosis in a hospital-based population with seizures in order to determine the existing knowledge and attitudes regarding the disorder and practices regarding its prevention and treatment.

Methods: One hundred and eighty two people attending an epilepsy clinic were administered a validated 16-item KAP questionnaire, the responses of which were assessed against responses obtained from experienced neurologists.

Results: Of the 182 respondents, 22 (12\%) believed that a worm was responsible for their seizures, while 94 (52\%) were aware of the link between worms and epilepsy in general. Despite this 150 (82\%) were unsure about the name and nature of the worm. In fact 89 (49\%) believed that the worm was acquired by eating cabbages rather than by consuming pork and by poor personal hygiene. Only 14 (8\%) had ever consumed pork. Of note, 56 (31\%) admitted visiting unqualified quacks who sucked out the worm through the nose.

Conclusions: In conclusion although the population was highly sensitized to the association between worms and epilepsy they did not appreciate its mode of transmission. Moreover the practice of visiting quacks to remove worms was quite prevalent.
\end{abstract}

Copyright $\odot$ 2015, Indian Epilepsy Society. Published by Reed Elsevier India Pvt. Ltd. All rights reserved.

\section{Introduction}

The parasitic infestation of human brain, neurocysticercosis (NCC), caused by the larval stage of the pork tapeworm, Taenia solium, is endemic in most parts of India and much of South and Central America, and parts of sub-Saharan Africa. ${ }^{1}$ Only recently, few community-based studies have documented transmission of the parasite and the high prevalence of its infestation in selected locations within India. ${ }^{2-4}$

\footnotetext{
* Corresponding author. Department of Neurology, Dayanand Medical College, Ludhiana 141001, Punjab, India. Tel.: +91 16124520243 ; fax: +91 161208383.

E-mail address: gagandeep_si@yahoo.co.uk (G. Singh). 
The International Task Force for Disease Eradication has recognized T. solium cysticercosis as one of the six disorders that are potentially eradicable. ${ }^{5}$ The control or eradication of any infectious disorder requires an assessment not only of the prevalence of infection in the community but also of knowledge about, attitudes towards and practices regarding (KAP) the disorder among members of the community. Control can be effectively implemented when the attitude of the community is scientifically appropriate and community members are supportive of the measures taken towards control or eradication. Hence, we undertook a knowledge, attitudes, and practices (KAP) survey that specifically addressed issues related to $\mathrm{T}$. solium cysticercosis among people with epilepsy attending a specialized epilepsy clinic in a hospital in Northwest India in order to determine aspects of prevention that need to be stressed in health education campaigns.

\section{Material and methods}

\subsection{Study sample}

The study sample comprised 182 consecutive people with epilepsy attending the adult epilepsy clinic of Dayanand Medical College, Ludhiana, India between 1st January 2007 and 30th June 2007. Informed consent was obtained from all study subjects. The project was approved by the Institutional Ethics Committee.

\subsection{Design and administration of questionnaire}

Questions and their answers were formulated by two neurologists with experience in the care of patients with NCC. They provided 10 questions each, of which identical items were omitted, leaving behind 16 questions. The questions were oriented towards the awareness of the nature of epilepsy in the subjects, awareness about NCC and the mode of acquisition, transmission and prevention of cysticercosis, available treatment options, and risk practices and behaviors that might facilitate transmission of the parasite. All questions were provided with multiple response answers of which only one response was deemed to be correct. The questions were then administered to another neurologist in order to determine appropriate responses.

The questionnaire was administered by a student investigator in the study team in strict confidentiality in a private room away from the epilepsy clinic in either English language or Punjabi, which is the vernacular language in the state of Punjab. Responses were also recorded by the student investigator.

\section{Results}

\subsection{Demographic characteristics of sample population}

The KAP questionnaire was administered to 182 patients [125 (69\%) males] [mean $( \pm$ SD) age: $24( \pm 14$ years)]. The cohort included $44(24 \%)$ students, although, most had completed their studies with 158 (87\%) being matriculate or under- matriculate (Table 1). Four of the respondents were medics or paramedics.

\subsection{Epilepsy characteristics}

Of the 182 respondents, 35 (19\%) presented with new-onset seizures, and 147 (81\%) had chronic epilepsy. Imaging (either CT or MRI) was undertaken in all patients and 31 (17\%) had evidence of NCC on their imaging studies.

\subsection{Knowledge about relationship between helminths and epilepsy and transmission of cysticercosis}

Regardless of presumed etiology of their epilepsy, 22 (12.1\%) respondents believed that a worm was responsible for their epilepsy (Table 2). However, 88 (48\%) were unsure regarding the cause of their epilepsy and considered hereditary factors ( $n=10 ; 6 \%)$, accidents $(n=25 ; 14 \%)$ and stress $(n=37 ; 20 \%)$ to be causally linked to their infirmity. Ninety four (52\%) respondents were aware that worms might be responsible for epilepsy. The majority (150; 82\%) were however unsure about the name or nature of the worm (i.e. tapeworm). Eighty nine (49\%) believed that the worm was found in cabbages and therefore could be acquired by eating raw cabbages. Only 14 respondents ( $8 \%$ ) held the view that the tapeworm could be acquired by consuming pork and 28 respondents (15\%) believed that infestation was associated with poor personal hygiene. According to 57 (31.2\%) respondents, the infestation could be diagnosed using a computerised tomographic scan (Tables 3, 4).

\subsection{Attitudes towards and knowledge about prevention of cysticercosis (Table 5)}

In all, $122(67 \%)$ respondents were willing to participate in a community program for screening or controlling $\mathrm{T}$. solium infestation. In the views of 68 respondents (37\%), good

Table 1 - Demographic characteristics of the study sample.

Demographic Characteristics

Responses

Gender

Male

Female $125(69 \%)$

Age (in years) (Mean \pm SD)

$57(31 \%)$

Educational qualification

Under-matriculate

Matriculate

Graduate

Post graduate

Higher

$24 \pm 14$

Profession

Medical/paramedical $4(2 \%)$

Teacher

Business

$1(1 \%)$

Student

Professional

Farmer

$73(40 \%)$

$85(47 \%)$

$17(9 \%)$

$3(2 \%)$

$3(2 \%)$

House wife

$31(17 \%)$

$44(24 \%)$

$6(3 \%)$

$15(8 \%)$

Others

$53(29 \%)$ 
Table 2 - Epilepsy characteristics.

\begin{tabular}{ll} 
& Responses \\
\hline Epilepsy code & \\
New-onset epilepsy & $35(19 \%)$ \\
Prevalent epilepsy & $147(81 \%)$ \\
Duration of seizures (in months) (mean \pm SD) & $70 \pm 74$ \\
Seizure frequency & \\
Single & $25(14 \%)$ \\
Sporadic & $47(26 \%)$ \\
Annual & $17(9 \%)$ \\
Biannual & $26(14 \%)$ \\
Monthly & $39(22 \%)$ \\
Weekly & $11(6 \%)$ \\
Daily & $17(9 \%)$ \\
Aetiology & \\
Neurocysticercosis & $31(17 \%)$ \\
Other & $151(83 \%)$ \\
\hline
\end{tabular}

personal hygiene could prevent transmission, though 42 (23\%) were of the impression that transmission could be prevented by avoiding consumption of cabbages and salad. The majority (101; 55\%) were unsure of the community-level measures required to prevent transmission of $\mathrm{T}$. solium.

\subsection{Risk behaviors}

Although 89 (49\%) respondents consumed animal products and meats, only 14 (8\%) admitted to pork consumption ever. Many (82; 45\%) believed that free-ranging pigs were the source of pork for human consumption and 57 (31.3\%) practiced open defecation albeit only occasionally. Personal hygiene was claimed to be good by 171 (94\%) respondents (Table 6).

\subsection{Myths associated with treatment of NCC}

Fifty six (31\%) respondents (including both, those diagnosed with NCC as well as others) admitted to visiting an unqualified

Table 3 - KAP items and response.

Responses

Relationship between helminths and epilepsy

What do you think has caused your epilepsy?

Hereditary factors

$10(6 \%)$

Worms

$22(12 \%)$

Accidents

$25(14 \%)$

Stress

$37(20 \%)$

Not sure

$88(48 \%)$

Can worms cause epilepsy?

Yes

$94(52 \%)$

No

$30(16 \%)$

Not sure

$58(32 \%)$

If worms can cause epilepsy, do you know the name of the worm that can cause epilepsy?

Roundworm

Boll worm

$0(-)$

Tapeworm

$1(1 \%)$

Hookworm

$1(1 \%)$

$0(-)$

Not sure

$150(82 \%)$

Not applicable
Table 4 - Knowledge about transmission of cysticercosis.

Responses

How does one get infected with this worm?

By eating raw cabbages

$71(39 \%)$

By eating chicken

$3(2 \%)$

By contact with dogs

$3(2 \%)$

By poor hygiene

$28(15 \%)$

Not sure $47(26 \%)$

Not applicable

$30(16 \%)$

Where is this worm normally located?

Cabbages

$89(49 \%)$

Pigs

$14(8 \%)$

Buffaloes

$0(-)$

Eggs

$3(2 \%)$

Not sure

$46(25 \%)$

Not applicable

$30(16 \%)$

If one person in the family has worms, can this be passed on to other persons in the family?

Yes

$26(14 \%)$

No

$79(44 \%)$

Not sure

$77(42 \%)$

individual (quack) who claimed to be able to suck out the worm with the help of a thin suction tube applied to the nose of the subject (Table 7). However, the majority (103; 57\%) were of the view that medications were nevertheless required in order to treat the disorder and only 7 (4\%) held the belief that

\section{Table 5 - Knowledge about and attitude towards} preventing cysticercosis.

\begin{tabular}{|c|c|}
\hline & Responses \\
\hline \multicolumn{2}{|l|}{ What methods best prevent from developing cysticercosis? } \\
\hline Avoid eating cabbages and salads & $42(23 \%)$ \\
\hline Maintain good personal hygiene & $68(37 \%)$ \\
\hline Do not eat any type of meat & $10(6 \%)$ \\
\hline Avoid eating pork & $9(5 \%)$ \\
\hline Not sure & $53(29 \%)$ \\
\hline \multicolumn{2}{|c|}{$\begin{array}{l}\text { If there were a mass screening program for cysticercosis that } \\
\text { involved giving stool and blood sample, would you participate? }\end{array}$} \\
\hline Yes & $143(79 \%)$ \\
\hline No & $39(21 \%)$ \\
\hline \multicolumn{2}{|c|}{$\begin{array}{l}\text { If there were a community based intervention program that } \\
\text { required certain medicines to be taken for } 1-2 \text { days as a mass } \\
\text { program to eliminate worm infestation, would you participate in } \\
\text { such a program? }\end{array}$} \\
\hline Yes & $122(67.0 \%)$ \\
\hline No & $60(33.0 \%)$ \\
\hline \multicolumn{2}{|c|}{$\begin{array}{l}\text { At the community level, what can be done to prevent transmission } \\
\text { of cysticercosis? }\end{array}$} \\
\hline Ensuring meat inspection & $38(21 \%)$ \\
\hline Banning the use of all meats & $23(13 \%)$ \\
\hline Banning the cultivation of salads in the fields & $13(7 \%)$ \\
\hline Disallowing pig farming & $7(4 \%)$ \\
\hline Not sure & $101(55 \%)$ \\
\hline \multicolumn{2}{|c|}{$\begin{array}{l}\text { What else can be done at community level to prevent transmission } \\
\text { of cysticercosis? }\end{array}$} \\
\hline $\begin{array}{l}\text { Improving public awareness about the transmission } \\
\text { of the disorder }\end{array}$ & $76(43 \%)$ \\
\hline Police checking of pork vendors & $17(9 \%)$ \\
\hline Microscopic screening of food material & $54(29 \%)$ \\
\hline Not sure & $35(19 \%)$ \\
\hline
\end{tabular}


Table 6 - Personal habits and hygiene.

Responses

$\begin{array}{lc}\text { What is the usual source of pork that is used for human } \\ \text { consumption? } \\ \text { Free ranging pigs } & 82(45 \%) \\ \text { Pigs from pig farms } & 61(33 \%) \\ \text { Both } & 21(12 \%) \\ \text { Not sure } & 18(10 \%) \\ \text { Have you ever consumed non vegetarian foods apart from eggs? } \\ \text { Yes } & 89(49 \%) \\ \text { No } & 93(51 \%) \\ \text { Do you/did you ever eat pork? } & \\ \text { Yes } & 14(8 \%) \\ \text { No } & 165(91 \%) \\ \text { Not sure } & 3(1 \%) \\ \text { Do you ever defecate in the open? } & \\ \text { Yes } & 57(31 \%) \\ \text { No } & 125(69 \%) \\ \text { Are you aware of free ranging pigs in your locality? } & \\ \text { Yes } & 59(32 \%) \\ \text { No } & 123(68 \%) \\ \text { Do you wash hands with soap before having your meals? } & 81(45 \%) \\ \text { Always } & 68(37 \%) \\ \text { Mostly } & 27(15 \%) \\ \text { Sometimes } & 6(3 \%) \\ \text { Never } & \\ \text { Do you wash hands with soap after defecating? } & 171(94.0 \%) \\ \text { Always } & 4(2 \%) \\ \text { Mostly } & 6(3 \%) \\ \text { Sometimes } & 1(1 \%) \\ \text { Never } & \end{array}$

removal through the nose was the only method of removing the worm from the brain.

\section{Discussion}

Taenia solium cysticercosis is one of the preventable causes of seizures and epilepsy. In order to reduce the burden of epilepsy attributable to cysticercosis, the transmission of T. solium needs to be controlled. ${ }^{6}$ A number of control interventions have been suggested to interrupt transmission of the parasite, but these are unlikely to be successful without positive change

Table 7 - Knowledge about treatment of cysticercosis and associated myths.

Responses

\begin{tabular}{lc} 
How would one treat this worm? & \\
Removal through the nose by persons specializing in & $7(4 \%)$ \\
$\quad$ this job & \\
Medications & $103(57 \%)$ \\
Surgery & $6(3 \%)$ \\
It resolves spontaneously & $2(1 \%)$ \\
Not sure & $34(19 \%)$ \\
Not applicable & $30(16 \%)$ \\
Have you been to a person or heard about a person who removes \\
$\quad$ worms through the nose? \\
Yes & $56(31 \%)$ \\
No & $126(69 \%)$ \\
\hline
\end{tabular}

in knowledge about, attitudes towards, and practices regarding the parasite and the disorder it causes.

Very few studies have evaluated the status of knowledge about, attitudes towards and practices concerning transmission of T. solium. ${ }^{7-10}$ One community-based survey in rural Mexico examined this aspect before and after an educational intervention oriented towards improving knowledge about and practices regarding T. solium. Before the intervention, 26\% of the population sampled was aware about human cysticercosis but immediately following the educational intervention, the proportion rose to $57 \%$. ${ }^{9}$ The socio-cultural setting of the Mexican survey was different from the population in our study. The majority of the households in rural Mexico reared pigs as a source of pork. Nearly $97 \%$ of the respondents in the Mexican survey were able to recognize pork infested by cysticerci. In comparison, only $7.7 \%$ of the respondents in our study remembered consuming pork ever.

Over half the respondents in our study were aware of the association between worms and epilepsy. This shows that the sample population was sensitized to the association between worms and epilepsy. One reason for this familiarity could be that the sample was drawn from a specialized epilepsy clinic and individuals with epilepsy attending the clinic often seek and are offered information about the link between helminths and epilepsy as a part of usual care.

A previous KAP survey in people with NCC also found that respondents were aware of the association between worms and epilepsy. ${ }^{11}$ In a different population comprising school teachers, the awareness of the association was only $26 \%{ }^{8}$

In association with two previous surveys in selected populations from India, ${ }^{11,8}$ this study uncovered gaps in knowledge about the parasite and the disorder. A unique finding in the present survey however, was that nearly half of the respondents $(89 ; 49 \%)$ held the belief that the worm responsible for epilepsy was found in cabbages and that the consumption of raw cabbages, other vegetables and salads could lead to worm infestation of the brain. As if to reinforce this belief, a number of subjects visited quacks in the countryside, who specialized in removal of worms using a mouth-held small, suction tube applied to the nose of people affected by epilepsy. The quacks then presented a cabbage bollworm to the subjects giving them the false impression that the cabbage bollworm was responsible for brain infestation. Some of the respondents visited these quacks despite having been provided counsel about the pointlessness of the exercise as part of usual care. The practice is not only unethical and scientifically baseless but also an unnecessary burden on the time and money of the people who visit these quack clinics. There is dire need for mobilizing public opinion and political and legal measures against this practice.

One limitation of this study was that it was undertaken in a highly-specialized population and hence its results may not accurately reflect community beliefs and practices. Furthermore, the benefits of recording community knowledge and practices should be reviewed in light of the failure to demonstrate sustainability and relevance of health and safe practices educational intervention in settings, where T. solium cysticercosis is endemic. ${ }^{9}$ For instance, in the Mexican study, the immediate benefits of the health education intervention were evident, a survey of knowledge, attitudes and practices 
six months later revealed that the benefits were not sustained. ${ }^{11}$ Similarly, a survey in Peru demonstrated that the practice of allowing pigs to stray away from enclosures freely for feeding on human faeces is difficult to change because this practice saves pig-rearing peasants the expenditure incurred on procuring food material for the pigs. ${ }^{12}$ The farmers optimize their profits by keeping investments to a minimum. Thus the driving force behind peasant's practices and attitudes to $T$. solium is economic benefit with total indifference to health, hygiene and safe practices.

In conclusion, this descriptive study demonstrates the prevailing state of knowledge about, attitudes towards and practices regarding the transmission and treatment of $T$. solium cysticercosis. Although, there is a high level of awareness of the relationship between helminths and epilepsy, there are misconceptions regarding the transmission and treatment of the disorder, which need to be corrected.

\section{Conflicts of interest}

All authors have none to declare.

\section{R E F E R E N C E S}

1. Garcia HH, Del Brutto OH. cysticercosis working group in Peru. Lancet Neurol. 2005;4:653-661.

2. Singh G, Singh P, Singh I, Rani A, Kaushal S, Avasthi G. Epidemiologic classification of seizures associated with neurocysticercosis: observations from a sample of seizure disorders in neurologic care in India. Acta Neurol Scand. 2006;113:233-240.

3. Prasad KN, Prasad A, Gupta RK, et al. Neurocysticercosis in patients with active epilepsy from the pig farming community of Lucknow district, north India. Trans $\mathrm{R}$ Soc Trop Med Hyg. 2009;103:144-150.

4. Rajshekhar V, Raghava MV, Prabhakaran V, Oommen A, Muliyil J. Active epilepsy as an index of burden of neurocysticercosis in Vellore district, India. Neurology. 2006;67:2135-2139.

5. Roman G, Sotelo J, Brutto Del, et al. Bull World Health Organ. 2000;78:399-406.

6. Garcia HH, Gonzalez AE, Gilman RH. Diagnosis, treatment and control of Taenia solium cysticercosis. Curr Opin Infect Dis. 2003;16:411-419.

7. Garcia-Noval J, Allan JC, Fletes C, et al. Epidemiology of Taenia solium taeniasis and cysticercosis in two rural Guatemalan communities. Am J Trop Med Hyg. 1996;55:282-289.

8. Mishra D, Kalra V, Aggarwal K. Awareness about taeniasis and neurocysticercosis among municipal schoolteachers in Delhi. J Commun Dis. 2007;39:225-228.

9. Sarti E, Flisser A, Schantz PM, et al. Development and evaluation of a health education intervention against Taenia solium in a rural community in Mexico. Am J Trop Med Hyg. 1997;56:127-132.

10. Kalage RE, Nyamongo Isaac K. Lay People's Knowledge, Perceptions and Practices Regarding the Transmission and Management of Human and Porcine Cysticercosis in Mbeya Rural District of Tanzania. Institute of Anthropology, Gender \& African Studies; 2009. http://africanstudies.uonbi.ac.ke.

11. Girotra M, Gera C, Abraham RR, et al. Awareness of Neurocysticercosis: a study from northwest India. Ann Indian Acad Neurol. Jan 2011;14:27-30.

12. Montano SM, Villaran MV, Ylquimiche L, et al. Neurocysticercosis: association between seizures, serology, and brain CT in rural Peru. Neurology. 2005;65:229-233. 